Dialectologia 24 (2020), 157-176.

ISSN: 2013-2247

Received 8 March 2018.

Accepted 30 June 2018.

\title{
VARIATION OF LEXICAL ITEMS AND THE CHANGING NEED OF IDENTITY PROJECTION: A STUDY ON MAPPILA MALAYALAM
}

\author{
Thapasya JAYARAJ $^{1}$ \& Rajesh KUMAR ${ }^{2}$ \\ Indian Institute of Technology Madras * \\ 1thapasya.jayaraj@gmail.com / 2rajesh@iitm.ac.in
}

\begin{abstract}
This paper analyses the variation in language at the lexical level and how the lexical choice of the speaker(s) affects in shaping their identity by obtaining primary data from the lexicon of the Mappila dialect of Malayalam spoken by the members of Mappila (Muslim) community of Kerala. Borrowings from Arabic, Persian and Urdu helped in shaping their identity as Mappilas because of the correlation between these languages and the Muslim religion. The paper shows how a variation in the lexical choice of the speakers could be socially motivated and involve in shaping and changing identities and lexical items or vocabulary clearly project the group identity and personal identity.
\end{abstract}

\section{Keywords}

dialect, variation, lexicon, identity, borrowing, socio-political factors

\section{VARIACIÓN LÉXICA Y LA NECESIDAD CAMBIANTE DE LA PROYECCIÓN DE IDENTIDAD:} UN ESTUDIO SOBRE MAPPILA MALAYALAM

\section{Resumen}

Este artículo analiza la variación en el lenguaje a nivel léxico y cómo la elección léxica de los hablantes influye en la configuración de su identidad al obtener datos primarios del léxico del dialecto

* Department of Humanities and Social Sciences, Indian Institute of Technology Madras (IIT Madras), Chennai 600036, Tamil Nadu, India. 
mappila del malayalam hablado por los miembros de la comunidad mappila (musulmana) de Kerala. Los préstamos del árabe, del persa y del urdu ayudaron a configurar su identidad como mappilas debido a la correlación entre estos idiomas y la religión musulmana. El artículo muestra cómo una variación en la elección léxica de los hablantes podría estar motivada socialmente e incide en la formación y el cambio de identidades y elementos léxicos o vocabulario que proyectan claramente la identidad del grupo y la identidad personal.

\section{Palabras clave}

dialecto, variación, léxico, identidad, préstamos, factores sociopolíticos

\section{Introduction}

Languages play complex roles in the society starting from formal and informal communications to being carriers of cultures. Various aspects of language have always been studied from different perspectives of linguistics as seen in the previous sociolinguistic studies on language and society, and they primarily focused on the variations in the language. Variation is identified as a fundamental characteristic of languages and variation linguistics has attempted to explain the network of harmonizing interactions with language and society. The influence of language in creating one's identity has been an important area of inquiry in many studies (Chambers 1993; Fischer 1958; Labov 1963; Labov 1976; Labov 2001; Trudgill 2002). The analysis of the interconnection between language variation and individual and social identities draws well-defined links between language variation, social factors and the social motivation. According to Woolard (1985), the analysis of various linguistic practices is matchlessly agreeable to the exploration of both behavioural and attitudinal dimensions. A sociologically informed reading of linguistic data can help take us beyond the limitations of finding the nexus between language and society (Woolard 1985). Lexical items or vocabulary clearly signifies the group and personal identities. Chassy (2014) noted that social groups often use symbols (logos, banners) to claim their identity. The symbols identify members within the group and state publicly the group identity to the outside world. Yet, an essential marker of one's group identity is the words used to communicate 
social realities (Chassy 2014). Coupland (2007) noted that speakers of a variety of language tend to modify their speech patterns according to various speech performance events and involve in a process of 'projecting'. Projecting is the partly controlled process of outward-directed self-representation through some manner of speech styling, how an individual creates patterns of linguistic behavior so as to resemble with or to be distinguished from a group (Coupland 2007). The phenomenon is very important in the context of variations in languages.

In the South Asian context, Indian linguistic complexity presents a composite cluster of variation as described by Emeneau (1956). A complex system of variations at different levels of linguistics expressions and different layers of society is a characteristic feature of languages in this region. Malayalam is one of the main Dravidian languages spoken in the Indian subcontinent. Studies on variations of Malayalam shows a great degree of variation at different levels and identifies different sociodialectal and regional dialectal variants (Nambothirippadu (1994); Devy, Sreenathan \& Koyippally 2015). This paper analyses the variation in language at the lexical level and how the lexical choice of the speaker(s) contribute to projecting their identity. The study develops by obtaining primary data from the lexicon of the Mappila dialect of Malayalam spoken by the members of Mappila (Muslim) community of Kerala. The Mappila dialect is considered as the most divergent with an intonation pattern of its own lexical items (Roy 1985). Mappila dialect of Malayalam was rich in its frequent use of borrowed words from Arabic, Persian and Urdu (Roy 1985; Asher \& Kumari 1997; Devy 2015 et al.). Trade link with the Arabs definitively influenced the language of Mappilas. At the same time, we cannot neglect the fact that there was a deliberate attempt to establish their identity as a member of the Mappila community, which was derived from the socio-political situation of that period. People from the Mappila community were highly determined to project their Mappila identity owing to social insecurities they had to face while accepting that religion (Miller 1992). Thus, the deliberate inclusion of Arabic, Persian and Urdu words in their speech assisted in exhibiting their identity. This made a clear variation between the Mappila dialect and other dialects of Malayalam at the surface level of language expressions. 
However, the socio-political conditions during the spread of Mappila community in the past had been changed over a period of time. The social motivation to project their identity as a Mappila excluding from members of other communities no longer exists other than in certain contexts, and thus the frequency of borrowed words from Arabic, Persian and Urdu are gradually reduced from their speech. The paper primarily focuses on the variation in the lexical choice of Mappila dialect speakers and the extra-linguistic factors, especially the reform in the community and development of formal education involved in creating the linguistic variation and also deals with the roles played by social motivation and individual and social identity dynamics in the lexical choice of the speakers.

\section{Language Variation and Identity}

Language is a fundamental factor in creating one's identity. The concept of identity has many implications and many theories were developed in defining it in disciplines of psychology, sociology, cultural studies and anthropology, among others. The identity of an individual was broadly classified into social identity and personal identity (Hall 2002, Turner 1982). It is defined as, "people's concepts of who they are, of what sort of people they are, and how they relate to others" (Abrams \& Hogg 1988). On the other hand, both social and personal identities are considered to be 'social', overlapping and interconnected systems in some of the approaches. Tajfel defined social identity as 'that part of an individual's self-concept which is derived from his membership to a social group (or groups), together with the value and emotional significance attached to it' (Tajfel 1978). No rigid distinction can, in fact, be made between personal and social identity. The identity of an individual is created in multiple strands through culture, community, experiences, living environment, class, status, language and so on. Language plays a significant role in moulding one's identity since it is the carrier of the qualities of an individual in social interactions. Linguistic identity caters to the personal and social identities of an individual. 
The identity of a person influences the linguistic choice of the individual, as well as the linguistic choice of the individual also plays a role in creating his/her identity in the society. It is an area which needs more complex analyses and discussions to arrive at a point of agreement among the different subjective understandings of the concept of 'identity'. Studies on language and language variations will lead to a better understanding of identity at both personal and social levels. A variety of a particular language is specifically important in studying identity since it represents the uniqueness of the individual and the speech community. For example, studying the idiolectal features of a person will lead to defining her/his linguistic characteristics and features and thereby lead to the understanding of that person's linguistic identity. The sociolinguistic studies carried out by Fischer (1958) and Labov (1963) are fundamentally pointing towards the identity that is reflected by the variant use of language by different social groups in the society. The importance of language as an identity marker at a group level is more evident: everyone is used to accent, dialect and language variations that reveal speakers' memberships in particular speech communities, social classes, ethnic and national groups' (Edwards 2009). The choice of a linguistic variable is purely dependent on the basis of which social group they belong to and how do they tend to portray themselves in a speech event.

While most of the studies in this area are based on variations at the phonological level, there were a few attempts to analyse the variation patterns at other levels and to provide sociolinguistic explanations had been carried out during the past few years. The study on the communal language variation in Bahrain (Holes 1983) analysed phonological and lexical variations in the languages of Sunnis and Shi's, two Arabic-speaking Muslim communities. Holes (1983) derives a clear correlation between the variation and the sociocultural status of the word in which variation occurred. Shi's have a tendency to make their speech 'sound Sunni' due to the pre-eminence and influence of Sunni variety as the 'high-status dialect' created by the sociocultural factors (Holes 1983).

In a recent study of Kumeyaay language variation by Field (2012), she analyses the lexical variations across two different Kumeyaay communities called 'lipay and Tiipay. It shows how the lexical choice of a speech community helps in establishing their identity in 
a social context. Margret Field writes: "Understanding dialect variation in terms of group identity and its connection to ecological and cultural contexts is helpful in explaining the intense lexical variation seen across Kumeyaay" (Field 2012: 563). The different variations in the languages that are initiated by the speech communities might rise in prestige by attaining a better identity value in the social hierarchy and there will be a tendency of society to move towards the dominant language variety in most of the instances and there will be a deep power play and matter of hegemony involved in the process of variation (Woolard 1985).

Lexical variations are considered to be the most obvious differences in comparison to the other dialects or variants, and something that the native speakers are aware of. Lexical variations, being more prominent in speech communities than other aspects of dialect variation such as phoneme inventories or variation in morphology or syntax, may also be prone to conscious manipulation and change. The motivation for including or accepting new vocabulary items in the lexicon of a speech community would be a conscious effort. The role of imitation is important in the initial stages of these variations. An established hypothesis in debates concerning language change is, 'once a change is initiated by a single individual (for whatever reason), its subsequent spread throughout a language community occurs when, and to the extent that, it is imitated by other speakers. This process indeed seems to operate in the area of new vocabulary' (Bright 1997). Similarly, in a drastic variation in the lexical choices across different social groups within the same speech community results in the creation of an independent lexicon and accepted within the community borders.

The perpetual debates surrounding the Hindi/ Urdu language politics existing in India exemplifies the association of language variation with the identity of the speaker(s) and communal consciousness. Even though the structure of both these languages is found to be similar in linguistic analysis, they have contrasting social identity markers associated with each of them, with Hindi being claimed as the language of Hindus and Urdu being the language of Muslims. Gumperz (1971) points out that everyday living in parts of India, particularly in the large cities and among the educated segments of those communities, requires some complex choices involving the distinction between Hindi and Urdu: 
On the conversational level the use of Hindi and Urdu forms is not simply a matter of birth and education. But just as it is customary for individuals to alternate between dialect and standard depending on the social occasion, so when using the standard itself the speaker may select from a range of alternatives. Hindi and Urdu therefore might best be characterized not in terms of actual speech, but as norms or ideal behaviour in the sociologist's sense. The extent to which a speaker's performance in a particular communication situation approximates the norm is a function of a combination of factors such as family background, regional origin, education and social attitude and the like (Gumperz 1971: 56-57).

This has become a well-known instance of socially determined variation in a language in South Asia which shows that the choice of a language variety has a lot to play in the socio-political scenario of the society. It has a role in establishing one's identity and statement of their personal profile. Hindi has more Sanskrit lexical items in it whereas in Urdu the words are mostly borrowed from Persian or Arabic. However, a change in the lexical items alone wouldn't be a valid reason to argue that these are indeed two different languages. At the same time the choice between these arrays of lexical items was a clear marker of the speakers' community identity. The community consciousness of the speaker determines what they name their language, Hindi or Urdu. The 'artificial divide' between these two languages was highly motivated by the socio-political situation present in the society and the identity associations concerning them (Khan 2006).

\section{Variations in Malayalam}

Variations of Malayalam exist at different levels of linguistic expressions like phonological, grammatical, semantic and lexical and are based on the region, social group - especially caste and religion, education, gender, age and so on (Devy et al. 2015). Variation studies on Malayalam have shown different dialects of Malayalam that have unique features when compared to other varieties. Apart from the regional dialectal variations, the socio-dialectal variations of Malayalam are easily distinguishable. Among 
the socio-dialects of Malayalam, the Mappila dialect and the Namboothiri (Brahmin community of the Hindu religion) dialect show a great degree of variation at different levels of linguistic expressions starting from the phonology. These variations help in identifying the speakers' identity as a member of a community to which they belong to.

The Namboothiri dialect of Malayalam is very different from its other dialects mainly because of its borrowings from Sanskrit. While considering the phonological system, Namboothiri dialect is the only dialect of Malayalam which has aspirated phonemes in casual speech. It has several consonant clusters too, which are very limited in casual speech of other dialects of Malayalam. Other than these Sanskritised characteristics, Namboothiri dialect has several borrowed Sanskrit expressions that are associated with their rituals and daily life language utterances. These linguistic features and speech patterns, derived from their culture and customs have become a part of the identity markers indicating the speakers' being members of the Namboothiri community Similarly, Mappila dialect of Malayalam acts as a unique identity marker for its speakers by marking them unique against the other dialect speakers of Malayalam. Kerala having a large minority of Mappilas, Malayalam used by them has absorbed a considerable amount of Arabic, Persian and Urdu loanwords and hence can be easily distinguished from the other sociolects (based on religion and caste) of Malayalam (Namboothirippadu 1994). The variations in their lexical items have helped in expressing and establishing their identity as a Mappila community member. For example, the following words have been borrowed from Arabic with some assimilations and used extensively by the speakers of Mappila dialect even though there are Malayalam expressions for them.

1. khalba 'mind' or 'heart'

2. hima:r 'donkey (used as a term to tease or abuse people)'

3. subaha 'early morning'

These variations finding way into their speech was a result of a conscious effort that was made by the community members in a particular socio-political situation at a particular point of time in the history. The need for showing their identity as a Mappila dialect speaker was crucial in those days to have social acceptance and equality. 


\section{Mappila Dialect and the Community Identity}

The majority of Mappila population in Kerala live in the Malabar region of Kerala. Malabar District was a part of the British East India Company controlled state in the preindependent India. The area is predominated with Hindu population. Most of the members of the Mappila community were originally converts from Hindu community, especially from its hierarchically "lower castes" (Correa 1849; Hardgrave Jr. 1964; Dale 1980). There was a clear socioeconomic motivation behind these conversions in the Malabar region because being a Mappila gave more social acceptance to them than the other castes which were considered to be inferior in the prevalent social norms. The conversion history of the Muslim religion in Kerala says that conversion to Islam mainly due to the motivation to be saved from the caste hierarchy and its injustice and suffering since Mappila religion does not have any caste hierarchy. Thus, there was a dire need to project their identity as a Mappila which was partly achieved by the deliberate inclusion of borrowed elements from Arabic, Persian and Urdu in their speech.

One of the other important developments was the development of a mixed language called Arabimalayalam for literary works. It followed the grammar and syntax of Malayalam and included lexical items from Arabic, Urdu and Tamil. It was written in Arabic script, with some new symbols to denote unfamiliar Malayalam consonants. Arabimalayalam is a mixed language that was formed as a conscious effort of Mappila community as a part of identity formation (Saidalavi 2013).

During those periods, their training in religious studies was more important in their community than even formal general education (Mohammed 2007; Miller 1992). The emergence of Mappila dialect as a variant from other dialects of Malayalam can thus be seen as a deliberate effort from the members of the Mappila community so as to project and establish their identity as a member of Mappila community and one who practices Mappila religion in the society. Later on, the social changes that happened in the society 
reflected in their concept of identity and attitude towards social acceptance which was also evident in the changes and variations that went into their language.

\subsection{Current Variations in Mappila Dialect}

This study explores a recent pattern of variation happening in the lexical choice amongst the speakers of Mappila dialect. It has been observed that the conscious effort that the speakers once put in to reveal their Mappila identity, especially through their speech by incorporating Arabic, Persian and Urdu borrowings in the lexical choice is undergoing a change and that they are reverting to the use of common Malayalam words with similar meanings used by the other dialect speakers. In their social interactions, especially with other community members, Mappila dialect speakers no longer tend to use the borrowed words and showcase their Mappila identity; rather, they tend to use the common lexical items in Malayalam and limit the use of their identity revealing factors from their speech. Likewise, the words given in examples (1), (2) and (3) are almost replaced by the dialectically common words like manasə 'mind', kałata 'donkey' and pularç̧a 'early morning' respectively.

This variation is not a random or isolated phenomenon. It has a definite gradual progress over a period of time that could be mapped across different generations of the dialect speakers. It has multi-layered socio-political aspects and implications and also reflects at the other levels of linguistic expressions. When closely analysed, the process of this variation is found to be a controlled phenomenon. This variation is very strong in the communication events within a mixed group of people from other communities. In these contexts, the Mappila dialect speakers tend to reduce the use of borrowed words from Arabic, Persian and Urdu and try to replace their lexical items with similar Malayalam words that are used by other dialect speakers. At the same time, within their own community and while in a closed social group of their own community members, the speakers retain their lexical choice with the borrowed words in considerably high frequency. 


\subsection{Method}

The data has been collected from speakers of five different age groups, up to 15 , 16-30, 31-45, 46-60 and 61 and above. Hypothesizing that the variation takes place over a period of time across different generations, the study chose these five age groups to identify the variation pattern over a period of time realized across generations. There were 20 speakers in each age group and their speech samples from three different contexts of duration 15 minutes have been recorded and analysed. The Different speech contexts were, two group conversations (Group I having two or three people, all of them being members of the Mappila community; and Group II being a mixed group, having in it people from different communities.) and a personal interview. Apart from these, a very limited data from public speeches (from religious and social public speeches and discourses) were analysed. The analysis of different speech contexts helped in understanding the speech behaviour and lexical choice of the speakers within the community and in a different social space. Thus, the interconnection of lexical choice and the identity representations of the Mappila dialect speakers could be analysed.

\subsection{Lexical Variation in Mappila Malayalam and Identity of the Speakers}

The variation pattern in the lexical choice of Mappila dialect speakers shows that there is a decrease in the use of Arabic, Persian and Urdu borrowed words eventually and that it is reflected across different age groups or generations. The younger generation has very few instances of borrowed words in their lexical choice whereas in the lexical choice of the older age groups, has more frequent occurrence of borrowed words. It is to be noted that this variation is more prominent in the public communicative events where the speakers communicate with the members of other communities. At the same time, true to the hypothesis, within a closed community setting involving only Mappila speakers, the speech patterns show more borrowed words, a strong indicator of the shared community identity. Table 1 shows the frequency of borrowed words in the lexical choice of speakers from different age groups and in different contexts. The frequency is 
measured as the average occurrence of the variants from the speech instances of 10 speakers in each age group for the duration of 15 minutes.

\begin{tabular}{|l|c|c|c|c|c|}
\hline & Up to 15 & $\mathbf{1 6 - 3 0}$ & $\mathbf{3 1 - 4 5}$ & $\mathbf{4 6 - 6 0}$ & $\mathbf{6 1}$ and Above \\
\hline Group I $^{\mathbf{1}}$ & 15 & 19 & 25 & 27 & 29 \\
\hline Group II $^{\mathbf{2}}$ & 15 & 14 & 18 & 25 & 21 \\
\hline Interview & 12 & 13 & 17 & 23 & 26 \\
\hline
\end{tabular}

1. Communication within a group of more than an individual, all are from Mappila community.

2. Communication within a mixed group of more than one individual in which non-Mappilas are included.

Table 1. Average number of occurrences of borrowed words in 15 minutes' speech.

In all the three contexts, the age group 61 and above shows the highest rate of choosing borrowed words in their speech and as the age decreases the use of borrowed words also decreases. As the newer generations come in, the expression of their Mappila identity through their speech, especially through the lexical choice they make declines. The group I context where the conversation happens exclusively between the people of Mappila community shows a higher frequency of borrowed words in their lexical choice. These instances show that Mappila dialects speakers continue to establish their community identity through their speech so as to establish their solidarity with other fellow members in some contexts.

The speech samples of the younger generation are of particular interest to this study because they have an almost similar speech pattern concerning their lexical choice in all the three contexts observed, with it almost moving towards the reduction of borrowed words. It shows that irrespective of the context, the younger generation has a general speech pattern which does not purposefully project their Mappila identity through their lexical choice. The data from the public speeches delivered during religious events were seen to have a high frequency of borrowed words and expressions. At the same time, the speeches in other contexts which included the participation of other community members like residential organization meeting had a low frequency of 
borrowed words. The choice of code mixing in their lexical choice is highly dependent on the context of their speech performance also.

\subsection{Borrowed Lexical Items and Variation in Mappila Malayalam}

The borrowed lexical items in Mappila dialect were used frequently in their daily communications. Almost all the words for their religious practices and customs are borrowed from Arabic or Persian. For example, words like:
4. dua: 'to pray'
5. su:ratta 'chapter of Quran'
6. rabba 'God'
7. nikka:ha 'wedding'

Even though these expressions are very natural in all Muslim communities in the world and equivalent expressions are present in Malayalam, Mappila speakers strictly choose to use these kinds of borrowed words to make a distinction from others. The Malayalam expressions like pra:rțikkuka 'to pray', deivam 'God', kalja:nam 'wedding', etc. are not at all used by the speakers by Mappila speakers in relation with their religious practices and customs. However, they use a unique expression in Malayalam padaç̧̧:n or padaç̧̧avan 'creator' to represent 'God', which is not used by other community members or dialect speakers.

It is to be noted that the lexical items related to religious practices, customs and rituals are still being used in significant frequency for the communication between the Mappilas. They begin their conversation by greeting each other with the Arabic phrase asala:mu alaikkum 'peace to you' which is met with the standard reply va: alaikkumusala:m 'peace to you too'. This is a strong social identity marker expressed through their speech. Even though it is a universal phenomenon in all Muslim communities but in for Mappila Malayalam speakers, this expression is used only with another Mappila to asserting their community solidarity not with a non-Mappila person. 
Similarly, if someone requests a Mappila dialect speaker to do something, instead of replying in the affirmative or in the negative, they would say infa:h atta:h 'if God wills'. This is again a strong marker of their Mappila identity as expressed through their lexical choice as part of their ritual to show their shared bond with the other person as members of the same community.

Some other words used in their day-to-day communications are also taken from Arabic, Persian and Urdu and the current variation is observed mostly in this area. For example: ${ }^{1}$
8. kabu:la 'agree'
9. sabu:ra 'forgive'
10. na:fta: 'breakfast'

The current variation in the lexical choice of Mappila dialect speakers seems to go along the removal of these words from the casual speech especially when she/he talks to another community member. These words are marginally and gradually vanishing from the lexical choice of the speakers and are getting replaced with Malayalam words that signifies similar objects or meanings. Similarly, the words used to abuse, tease or curse people when the speaker is angry were also largely borrowed from these foreign languages and the present variation seem to elicit an influence here too, with these words also getting gradually replaced with synonymous Malayalam words used commonly across its various dialects. For example,
11. hima:ra 'donkey'
12. ka:fir 'non-believer'
13. ibli:sa 'devil'

Other dialect speakers use the Malayalam expressions ka^uța, avi६vasi and pi६açə respectively to represent similar concepts in example 11 to 13.

\footnotetext{
${ }^{1}$ Malayalam words for agree, forgive and breakfast are sammațam, ma:ppo and pra:tal or ça:ja (literally means 'tea' but used as a general term for breakfast in Malabar region of Kerala) respectively.
} 
Why has this community made a conscious effort towards this new variation in their lexical choice even though they had once created a linguistic identity for themselves? Why do they need to underplay their identity rather than project them as an isolated community in the society through their established speech pattern? Which are the lexical items that they continue to retain in their present variants of daily speech and what are the contexts of occurrences for these items. How is the identity of the speaker marked in these contexts? Analysing the patterned variation happening in the Mappila dialect would answer all these questions related to the link between community identity, social factors and variation in lexical choice.

\subsection{Mappila Identity and Changing Needs: Role of Modern Education}

The social backgrounds of the subjects of the current study show a clear correlation between the educational background, identity consciousness and language variation. The members of the Mappila community are undergoing through two different education practices, the religious studies from Madrasas ${ }^{2}$ and the general formal education. The former is strictly followed by most of the members of the community up to the secondary level irrespective of the age group whereas the older generation did not give importance to the later in earlier days. This tendency gradually changed over a period of time and the Mappilas started following both the systems of education equally by recent decades. Among these education systems, the Madrasa education system played a great role in establishing their Mappila identity at the same time the general formal education practices contributed to their social and public life. Figure 1 shows the percentage of the number of formally educated in general education system in each age group.

\footnotetext{
${ }^{2}$ Educational institutions established by Mappila community in Kerala primarily focused to teach the religion and Arabic language.
} 


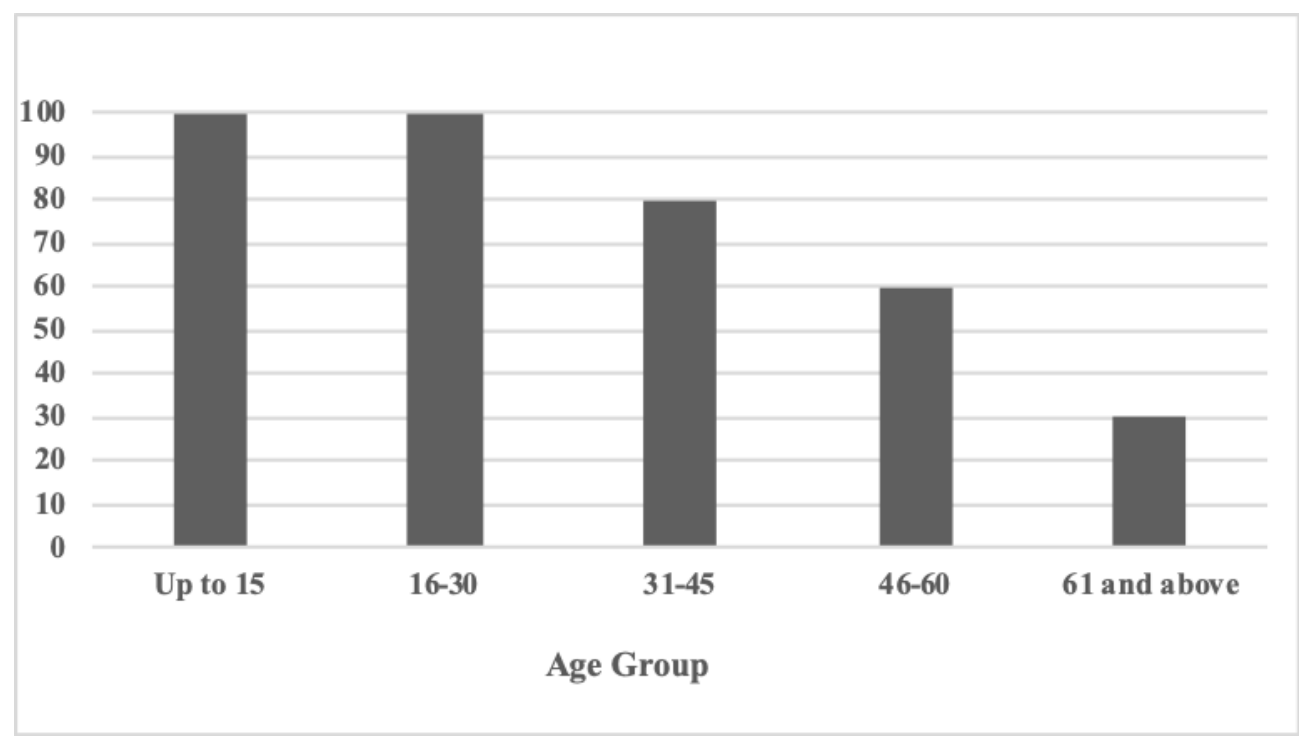

Figure 1. Formally educated individuals (in percentage).

The younger generations of age group of 16-30 are the most educated group as compared to people from other age groups in Mappila community and shows a clear variation in lexical choice by reducing the borrowed words and code mixing in their speech. They no longer make a conscious effort to express their Mappila identity through their speech rather choose to speak like any other dialect speakers in the region. The speakers from the age group up to 15 are currently school going children and they also show a reduced frequency of lexical borrowings in their speech. On the other hand, the older generations tend to have more code switching in their speech patterns which directly correlates with their formal education level. Hence by comparing the data from each category indicates a correlation between the pattern of variation and the speakers' education background.

Language is an easy way to express the identity of a person to others in a social context. The understanding of this characteristic of language might have led the Mappila community members to make variations in their speech patterns earlier. Borrowing sounds and lexical items from Arabic (the language of their religion), Persian and Urdu were found to be an easy and effective way of achieving this goal. Soon after the conversion of religious faith from being a lower caste Hindu to a socially accepted Mappila. expressing their identity as a member of the Mappila community was a 
necessity for the people at that point in time, as it promised better social status and approval.

This situation has changed drastically and revealing the Mappila identity through their speech no longer gives them a higher social status or acceptance in the society. There is now a need amongst these community members to express the spirit of togetherness to the larger society through their speech than to show their cultural and social uniqueness. This could have resulted in a need for limiting the identity indicating elements in their daily speech lexicon, requiring them to introduce the current variant of the Mappila dialect, thus making them a part of the larger community. In the context of the present study, people tend to relate to their larger identity as a 'Malayalee' (a native speaker of Malayalam) than marking themselves unique from the larger society. Identity is constructed through the connections between language variation and social meaning. The foundation of modern education system through social reformation movements have played a great role in creating a new social attitude of equality between the people of Kerala irrespective of the earlier existed religious hierarchies and shows a tendency towards a dialect levelling process among the verities of Malayalam. This has been reflected in the identity consciousness of the Mappila dialect speakers and resulted in a variation in their lexical choice as seen in the pattern of speech from the past to the present. Language, especially the lexical choice persisted as a constant medium for expressing one's identity according to the changing needs of the speech community from time to time to balance with the changing socio-political needs emerged out of the sociopolitical situations.

\section{Conclusion}

This paper shows that the motivation for language variation highly depends on the socio-political factors, in this case among the speakers of Mappila dialect. This is manifested in their language use at all linguistic levels, of which the lexical level interests the current paper and thereby has visibly helped in moulding their identity. Borrowings 
from Arabic, Persian and Urdu helped in shaping their identity as Mappilas because of the correlation between these languages and the religion to which they belong. But the speakers of the community show a deliberate withdrawal of these borrowed words over a period of time in accordance with the prevailing socio-political scenario and thereby, result in an alteration in expressing their identity. Apart from words that have religious denotations, the borrowed words of daily use from these languages are very few at present. The analysis of variations in the lexical choice of the speakers according to their age shows a significant variation between generations implying that the gradual systematic variation is taking place over a period of time. The variation pattern is dependent upon the situation in which the speaker is involved. The need for projecting a specific identity of an individual would vary according to the change in the socio-political scenario. The Mappila dialect speaking community uses a variation in lexical choice as an effective tool of identity manipulation and liaison since a variation in the pragmatic use of language can shape their identity to suit the varying socio-political situations. The variation is realized with a native-like proficiency in the younger generations as it has been going through a maturing period and having been established by practice by the older generations. All linguistic variations would be systematic and progressive in nature and there would be a clear motivation behind such a variation. The present variation happening in the lexical choice of the Mappila dialect speakers is also a result of a clear motivation of converting their identity according to the changing needs of real-time conversation contexts, socio-political situations and the new social consciousness as seen in every living languages of the world.

\section{References}

Abrams, D. \& M. A. Hogg (1988) "Comments on the motivational status of self-esteem in social identity and intergroup discrimination", European journal of social psychology, 18(4), 317334.

ASHER, R. E. \& T.C. KUMARI (1997) Malayalam, London and New York: Routledge. 
BRIGHT, W. (1997) "Social Factors in Language Change", in Florian Coulmas (ed.), The Handbook of Sociolinguistics, Oxford: Blackwell, 81-91.

Chambers, J. K. (1993) "Sociolinguistic Dialectology", in Dennis R. Preston (ed.), American Dialect Research: An Anthology Celebrating the 100th Anniversary of the American Dialect Society, Amsterdam \& Philadelphia: John Benjamins, 133-164.

CHASSY, P. (2014) “How Language Shapes Social Perception”, Language and Identity: Discourse in the World, England: Bloomsbury Academic, 36-54.

Coupland, N. (2007) Style: Language Variation and Identity, Cambridge: Cambridge University Press.

CORREA, G. Lendas da India [Eng. trans. Henry Stanely (1849) Three Voyages of Vasco de Gama, Hakluyt Society, London, 155f, quoted in Miller (1992), 56.

DALE, S. F. (1980) Islamic Society on the South Asian Frontier: The Mappilas of Malabar, 19481922, Oxford: Oxford University Press.

Devy, G. N., M. Sreenathan \& J. Koyippally (eds). (2015) People's Linguistic Survey of India. The Languages of Kerala and Lakshadweep, volume 15, New Delhi: Orient Blackswan.

EDWARDS, J. (2009) Language and identity: An introduction, Cambridge, UK: Cambridge University Press.

EMENEAU, Murray B. (1956) “India as a Linguistic area”, Language 32 (1), 3-16.

FIELD, M. (2012) “Kumeyaay Language Variation, Group Identity, and The Land", International Journal of American Linguistics, 78(4), 557-573.

FISCHER, J. L. (1958) "Social influences on the choice of a linguistic variant", Word, 14(1), 47-56.

GUMPERZ, J. J. (1971) Language in Social Groups, Stanford, CA: Stanford University Press.

HALL, J. K. (2002) Teaching and researching: Language and culture, Harlow: Longman.

HardgraVe, R. L. (Jr.) (1964) "Caste in Kerala: A Preface to the Elections", The Economic Weekly, 16, No. 47, 21 Nov. 1964.

Holes, Clive D. (1983) "Patterns of Communal Language Variation in Bahrain", Language in Society, 12(4), 433-457.

KHAN, A. J. (2006) Urdu/Hindi: An Artificial Divide: African Heritage, Mesopotamian Roots, Indian Culture \& British Colonialism, New York: Algora Publishing.

LABOV, W. (1963) "The social motivation of a sound Change", Word, 19, 273-307.

LABOV, W. (1976) Sociolinguistic Patterns, USA: University of Pennsylvania Press.

LABOV, W. (2001) Principles of Linguistic Change, Vol. 2, Social Factors. USA: Blackwell.

MILLER, R. E. (1992) Mappila Muslims of Kerala: A Study in Islamic Trends. Orient Logman. 
Mohammed, U. (2007) Educational Empowerment of Kerala Muslims: A Socio-Historical Perspective, Kerala: Indian Council of Historical Research.

NAmbothIRIPPADU, Usha (1994) Samoohya Bhasha Shastram (Mal), Thiruvananthapuram: Kerala Bhasha Institute.

RoY, C. J. (1985) Malayalam Dialects. History of Malayalam Language, University of Madras.

SAIDALAVI, C. (2013) A Sociolinguistic Evaluation of Arabi Malayalam, Unpublished Thesis, Department of Studies in Linguistics, University of Mysore.

TAJfel, H. (ed.) (1978) Differentiation between Social Groups: Studies in the Social Psychology of Intergroup Relations, London: Academic Press.

TRUdGILL, P. (2002). Sociolinguistic Variation and Change, Edinburgh: Edinburgh University Press.

TURNER, J. C. (1982) "Towards a Cognitive Redefinition of the Group", in Henri Tajfel (ed.), Social Identity and Intergroup Relations, New York: Cambridge University Press, 15-40.

Woolard, K. A. (1985) "Language Variation and Cultural Hegemony: Toward an Integration of Sociolinguistic and Social Theory" American Ethnologist, 12(4), 738-748. 